\title{
Numerical models of mass transfer during ripening and storage of salami
}

\author{
Angelo Fabbri, Chiara Cevoli, Giulia Tabanelli, Fausto Gardini, Adriano Guarnieri \\ Department of Agricultural and Food Science, University of Bologna, Italy
}

\begin{abstract}
Ripening, in the dry sausages manufacturing process, has an influence over the main physical, chemical and microbiological transformations that take place inside these products and that define the final organoleptic properties of dry sausages. A number of study about the influence of ripening conditions on the main chemical and microbiological characteristics of dry sausages is available today. All these studies indicate that the final quality and safety standards achieved by the sausage manufacturing process can be considered to be strictly dependent from the specific ripening conditions. The water diffusion inside a seasoned sausage is surely an aspect of primary importance with regard to the quality of final product. As a consequence the aim of this research was to develop two parametric numerical models, concerning the moisture diffusion physics, describing salami ripening and storage. Mass transfer equations inside the sausage volume were numerically solved using a finite element technique. A first model describes diffusion phenomena occurring inside the salami and the exchange phenomena involving the surface of the product and the environment. After the ripening, the salami are stored in waterproof packaging, consequently an additional model able to describe also the evaporation and condensation phenomena occurring between the salami surface and the air in the package, was developed. The moisture equilibrium between salami surface and conservation atmosphere is mainly ruled by the temperature changes during storage. Both models allow to analyze the history of the moisture content inside the salami and are parametrised on product size and maturation/storage conditions. The models were experimentally validated, comparing the numerical outputs of the simulations with experimental data, showing a good agreement.
\end{abstract}

\section{Introduction}

Dry sausages are the result of a fermentation process and a ripening period during which the products reach the desired characteristics.

Correspondence: Chiara Cevoli, P.zza Goidanich n.60 - 47521, Cesena (FC). E-mail: chiara.cevoli3@unibo.it

Key words: numerical simulation, water diffusion, salami, ripening, storage.

CC Copyright A. Fabbri et al., 2013

Licensee PAGEPress, Italy

Journal of Agricultural Engineering 2013; XLIV(s2):e62

doi:10.4081/jae.2013.s2.e62

This article is distributed under the terms of the Creative Commons Attribution Noncommercial License (by-nc 3.0) which permits any noncommercial use, distribution, and reproduction in any medium, provided the original author(s) and source are credited.
From several centuries, different kind of dry fermented sausages have been produced in the Mediterranean area (Toldrá et al., 2007; Zeuthen, 1995). The wide variety of dry fermented sausages is a consequence of variations in formulation, raw material, and manufacturing processes which come from the traditional habits of different countries and regions (Zanardi et al., 2010). Often sausages get different names according to geographic origin (Toldrá, 2006). Salami are typical European dry sausage manufactured with pork, beef, or veal, added with salt, spices, and sometimes herbs and/or other ingredients.

The primary European countries producing salami with a traditional seasoning process are Germany, Italy, Spain, France, and Hungary, with an amount of production of several hundred-millions $\mathrm{kg}$ per year, and consequently it is clear that ripening and storage treatment plays an important role (Bertolini et al., 2006). In the dry sausages industry, ripening is nowadays considered to be one of the most important stages of the integrated supply chain needed to ensure that the end products have the final requirements in terms of quality and safety standards (Grassi et al., 2005). Particularly the ripening stage influences over the main physical, chemical and microbiological transformations that take place inside of salami.

A large number of study regarding the influence of ripening conditions on the microbiological, physical and chemical properties of dry sausages is available (Baldini et al., 2000; Campbell-Platt, and Cook, 1995; Zanardi et al., 2010). All these researches show that the final quality and safety standards achieved by the sausage manufacturing process can be considered to be strictly dependent from the way the ripening stage is designed and carried out (Rizzi, 2002).

Two simultaneous mass transport phenomena occur inside the matrix during the drying process: water and solutes transfer. Many theoretically and experimentally study about transfer of water and solutes through meat and meat products matrices are reported in literature (Costa-Corredor et al., 2009; Graiver et al., 2006; Hansen et al., 2008; Sabadini et al., 1998; Unal et al., 2004).

As reported in many specific reviews, the recent progress in computing efficiency coupled with reduced costs of codes has set out the numerical simulation as a powerful tool to study many food processes with the aim of providing effective and efficient plant design or operating solutions (Scott and Richardson, 1997; Xia and Sun, 2002; Wang and Sun, 2003; Norton and Sun, 2006; Smale et al., 2006; Verboven et al., 2006; Mirade, 2008). In this regard, the numerical simulation was used to study the mass transfer in various food during drying, baking, freezing and ripening (Mirade, 2008; Sakin et al., 2007; LemusMondaca et al., 2013; Floury et al., 2008).

The aim of this research was to develop two parametric numerical models, concerning the moisture diffusion physics, describing salami ripening and storage. Mass transfer equations inside the sausage volume were numerically solved using a finite element technique. A first model describes diffusion phenomena occurring inside the salami and the exchange phenomena involving the surface of the product and the environment, while a second one describes also the evaporation and condensation phenomena occurring between the salami surface and the air in the package. The models were experimentally validated, comparing the numerical outputs of the simulations with experimental data. 


\section{Materials and methods}

\section{Ripening model}

The equations regarding mass transfer inside the salami during ripening were solved using Comsol Multiphysics 4.3 (COMSOL Inc., Burlington, MA, USA), a commercial partial differential equations solver, based on finite element technique.

The model considers both diffusion phenomena inside the salami and exchange phenomena between product and air of the ripening environmental.

In order to limit the computation time, an one-dimensional model was built and then, with a simple geometric operation, a 2D model can be visualized. In fact, salami geometry is axisymmetric and a simple radius, comprised between the longitudinal axis and the external cylindrical surface, was considered. The geometry dimensions reflect the real ones of the salami considered (radius, $r: 20 \mathrm{~mm}$, length: $200 \mathrm{~mm}$ ).

The moisture transfer is governed by Fick's law:

$$
\frac{\partial C}{\partial t}=D_{H 2 O}\left(\frac{\partial^{2} C}{\partial x^{2}}\right)
$$

where $C$ is calculated moisture concentration $\left(\mathrm{mol} \mathrm{m}^{-3}\right)$ at time $t$ and coordinate $x$.

The mass diffusivity $\left(D_{H 20}\right)$ through the involved material was estimated by an inverse method $\left(2.74 \mathrm{E}-12 \mathrm{~m}^{2} \mathrm{~s}^{-1}\right)$.

The initial and boundary conditions are:

- initial moisture concentration $\left(C_{i n R}\right)$ was considered constant in space and defined as following:

$$
C_{i n R}=\left(\frac{M_{H 2 O}}{P M_{H 2 O} \cdot V_{s}}\right) \rightarrow C_{i n R}=\left(\frac{X_{i n R} \cdot \rho_{s}}{P M_{H 2 O}}\right)
$$

where $X_{\text {inR }}$ is the initial moisture content on dry basis (experimental determination: $1.14 \mathrm{kgkg}^{-1}$ ), $\rho_{s}$ is the salami density (experimental determination: $600 \mathrm{kgm}^{-3}$ ), while $P M_{H 2 O}$ is the molecular weight of the water $\left(0.018 \mathrm{~kg} \mathrm{~mol}^{-1}\right)$;

- on the interface between the surface of the salami and the air, a flux condition was imposed:

$$
N_{R}=k_{e x}\left(C_{b o u n d}-C\right)
$$

being $N_{R}\left(\mathrm{~mol} \mathrm{~m}{ }^{-2} \mathrm{~s}^{-1}\right)$ the flux, $k_{e x}\left(\mathrm{~ms}^{-1}\right)$ the mass exchange coefficient and $C_{\text {bound }}$ the moisture concentration of salami at equilibrium.

Concerning the mass exchange coefficient ( $\left.k_{e x}: 1 \mathrm{E}-6 \mathrm{~ms}-1\right)$, it can vary within very broad limits, without problems of physical model fidelity: for high values could be compromised convergence, while for small values could introduce an artificial resistance to the moisture passage. The value must therefore be determined empirically by choosing a level slightly lower than that which causes convergence problems.

Moisture concentration of salami at equilibrium was defined by following equation:

$$
C_{\text {bound }}=\left(\frac{X_{\text {bound }} \cdot \rho_{s}}{P M_{H 2 O}}\right)
$$

where $X_{\text {bound }}$ is the dry basis moisture content at equilibrium. This value was determined by using the Oswin law:

$$
X_{\text {bound }=} A\left[\frac{a_{w}}{\left(1-a_{w}\right)}\right]^{B}
$$

being $a_{w}$ the room relative humidity (0.7), while A e B are two parameters extrapolated by fitting absorption isotherms with 0swin law. In this research, the absorption isotherms, at different temperatures, of a similar product to salami, were used (Palatoglu et al., 2011):

$$
A=129028 \exp ^{-0.033 T}
$$

$$
B=0.1199 \exp ^{0.0053 T}
$$

where $T$ is the temperature $(\mathrm{K})$.

Model was validated by comparing dry basis moisture content, numerically and experimentally determined on salami after 12 an 24 days of ripening at $75 \%$ of relative humidity.

\section{Storage model}

For the model of salami storage in waterproof packaging, the same software geometry and physical parameters of the salami $\left(D_{H 2 O}\right)$ used for the ripening model were considered.

The model considers both diffusion phenomena inside the salami and exchange phenomena (evaporation and condensation) between product and headspace. The total water mass of the salami/air system was imposed constant.

Even in this case, the phenomenon of mass transfer is governed by Fick's law.

The initial and boundary conditions are:

- initial moisture concentration $\left(C_{i n}\right)$ was considered constant in space and defined as follows:

$$
C_{i n S}=\left(\frac{M_{H 2 O}}{P M_{H 2 O} \cdot V_{s}}\right) \rightarrow C_{i n S}=\left(\frac{X_{i n S} \cdot \rho_{s}}{P M_{H 2 O}}\right)
$$

where $X_{\text {ins }}$ is the initial dry basis moisture content (experimental determination: $0.97 \mathrm{kgkg}^{-1}$ );

- on the interface between the surface of the salami and headspace, a flux condition $\left(N_{S}\left[\mathrm{molm}^{-2} \mathrm{~s}^{-1}\right]\right)$, as function of the partial pressure, was imposed:

$$
N_{S}=k_{e x}\left(C_{\varphi_{a i r}}-C_{a w_{a i r}}\right)
$$

where:

$$
C_{\varphi_{a r}}=\left(\frac{X_{\varphi_{a r}} \cdot \rho_{a i r}}{P M_{H 2 O}}\right)
$$

moisture concentration of the air/water vapour mixture;

$X_{\varphi_{a r}}=\left(\frac{P M_{H 2 O}}{P M_{\text {air }}}\right) \cdot\left(\frac{\varphi_{\text {air }} \cdot P_{\text {airsat }}}{P_{\text {atm }}-\varphi_{\text {air }} \cdot P_{\text {airsat }}}\right):$

moisture content in the air/water vapour mixture (Mujumdar and Menon, 1995); 


$$
C_{a w_{a r}}=\left(\frac{X_{a w_{a r}} \cdot \rho_{a i r}}{P M_{H 2 O}}\right)
$$

moisture concentration of the air near to salami;

$$
X_{a w_{a r}}=\left(\frac{P M_{H 2 O}}{P M_{a i r}}\right) \cdot\left(\frac{a w_{a i r} \cdot P_{a i r S a t}}{P_{a t m}-a w_{a i r} \cdot P_{a i r S a t}}\right):
$$

moisture content in the air near to salami (Mujumdar and Menon, 1995);

$$
\rho_{\text {air }}=\left(\frac{P_{\text {atm }} \cdot P M_{\text {air }}}{R T}\right): \text { air density }\left[\mathrm{kgm}^{-3}\right] ;
$$

$P_{a t m}:$ atmospheric pressure $[1 \mathrm{E}+5 \mathrm{~Pa}]$;

$P M_{\text {air: }}$ air molecular weight $\left[28.84 \mathrm{gmol}^{-1}\right]$;

$R$ : gas constant $\left[8.314 \mathrm{JK}^{-1} \mathrm{mo}^{-1}\right]$;

$\mathrm{T}$ : temperature $[\mathrm{K}]$;

$$
P_{\text {airsat }}=\left(10^{\left(8.07131-\frac{1730.63}{233.426+T}\right)} \cdot \frac{P_{\text {atm }}}{760}\right):
$$

saturation pressure of water vapour in air as function of temperature (August-Antoine, 1888) [Pa];

$\varphi_{\text {air }}=\frac{P_{\text {air }}}{P_{\text {airsat }}}:$ relative humidity of air/water vapour mixture;

$P_{\text {air }}=\frac{M_{\text {air }} \cdot R T}{P M_{H 20} \cdot V_{\text {air }}}$ : partial pressure of water vapour $[\mathrm{Pa}]$;

$V_{\text {air }}$ : headspace volume $\left[\mathrm{m}^{3}\right]$;

$$
M_{\text {air }}=\left(M_{\text {Tot }}-M_{S}-M_{L q}\right) \text { : }
$$

water mass in the headspace [kg] calculated considering mass conservation equation;

$M_{\text {Tot }}=M_{S_{d}} \cdot X_{\text {in }}:$ total water mass in the system $[\mathrm{kg}]$

$M_{S d}=V_{s} \cdot \rho_{s}:$ dry salami mass $[\mathrm{kg}]$

$V_{s}=\left(r^{2} \pi L\right)$

salami volume ( $r$ : salami radius, $L:$ salami lengh) $\left[\mathrm{m}^{3}\right]$;

$M_{S}=\left(\bar{\rho}_{H 2 O S} \cdot V_{s}\right):$ water mass in salami $[\mathrm{kg}] ;$

$$
\bar{\rho}_{H 2 O S}=\bar{C} \cdot P M_{H 2 O}:
$$

mean water density as function of mean water concentration $\left[\mathrm{kgm}^{-3}\right]$

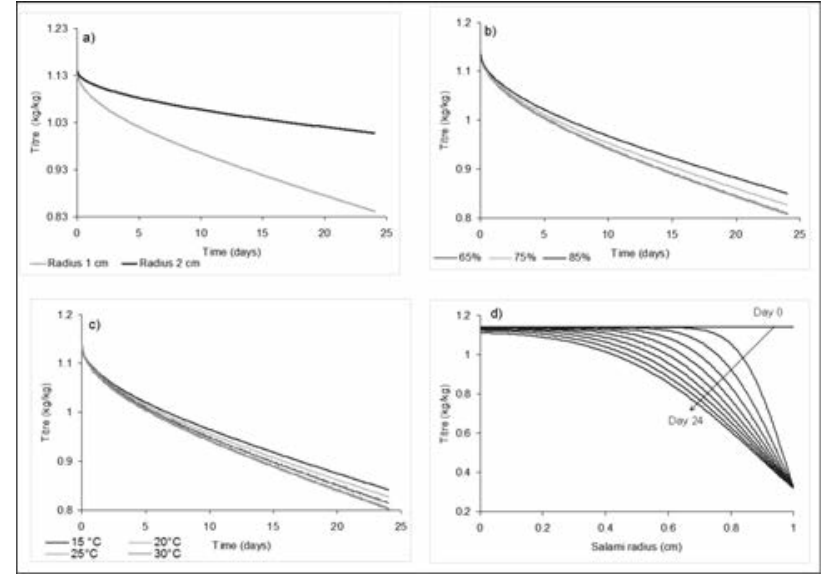

Figure 1. Mean dry basis titres of water, determined numerically, as function of salami radius (a), humidity (b), temperature (c) and position inside of salami (c).

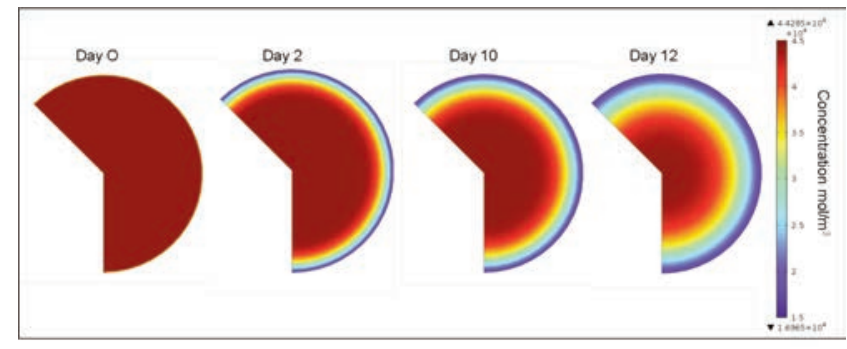

Figure 2. Simulated moisture concentration inside of a salami characterized by a radius of $1 \mathrm{~cm}$, for 12 day of ripening.

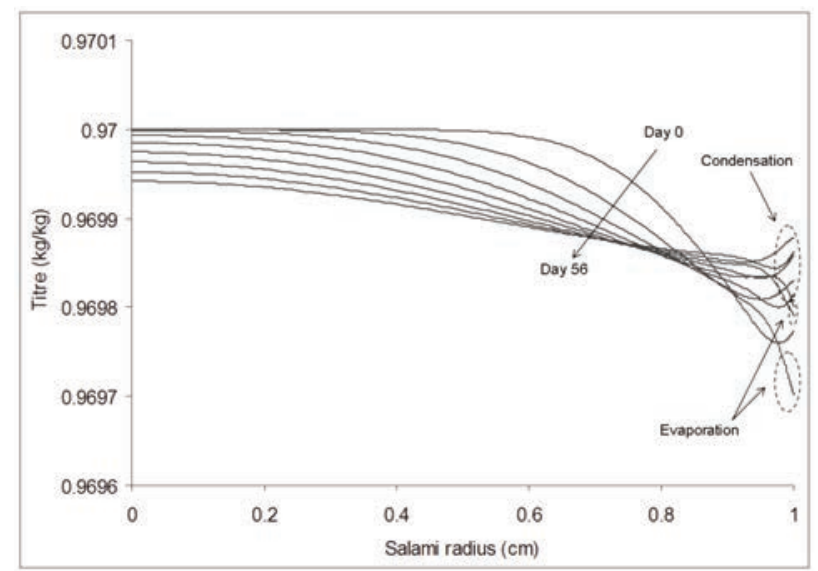

Figure 3. Dry basis titre of water as function of storage time and position inside of salami. 


$$
\frac{d M_{L q}}{d t}=F c-F e
$$

water mass conservation equation as function of evaporation and condensation phenomenon $[\mathrm{kg}]$;

$$
F c=K c \cdot\left(\varphi_{\text {air }}-1\right) \cdot\left(\frac{M_{\text {air }}}{M_{\text {Tot }}}\right) \cdot \bar{A}:
$$

mass flow of condensing water (when air/water vapour humidity is greater or equal to 1$)\left[\mathrm{kgs}^{-1}\right]$;

$$
F e=K e \cdot\left(1-\varphi_{\text {air }}\right) \cdot\left(\frac{M_{L q}}{M_{\text {Tot }}}\right) \cdot \bar{A}:
$$

mass flow of evaporating water (when air/water vapour humidity is less than 1) $\left[\mathrm{kgs}^{-1}\right]$;

$$
\bar{A}=L \pi \cdot\left(r+r_{c}\right)
$$

mean exchange area $\left(r_{c}\right.$ : packaging salami);

$K c$ : condensation parameter [1E-3 $\left.\mathrm{kgs}^{-1} \mathrm{~m}^{-2}\right]$;

$K e$ : evaporation parameter [1E-3 $\left.\mathrm{kgs}^{-1} \mathrm{~m}^{-2}\right]$;

$$
a w_{\text {air }}=\left(\frac{\left(\frac{X_{H 2 O S}}{A}\right)^{\left(\frac{1}{B}\right)}}{1-\left(\frac{X_{H 2 O S}}{A}\right)^{\left(\frac{1}{B}\right)}}\right):
$$

relative humidity of air near to salami by using Oswin law;

$$
X_{H 2 O S}=\left(\frac{\bar{C}_{c} \cdot P M_{H 2 O}}{\rho_{s}}\right) \text { : }
$$

dry basis moisture content of salami surface as function of mean water concentration determined on the exchange surface $\left(\bar{C}_{c}\right)$.

Model was validated by comparing the dry basis moisture content, numerically and experimentally determined on salami after 56 days of storage in waterproof packaging.

\section{Results}

To validate the ripening model, experimental and calculated values of dry basis moisture content determined after 12 and 24 days of ripening at $75 \%$ of humidity, were compared. Experimentally values of $0.978 \pm 0.072$ and $0.841 \pm 0.049$ were found, respectively for 12 and 24 days of ripening, while values of 0.962 and 0.835 were determined by model. The simulated and experimental data appear to be in good agreement. This result shows that the numerical model is able to reproduce the mass transfer phenomenon inside of salami.

To evaluate the effect of salami size on the mass transfer, the mean moisture con content on dry basis, determined numerically, for a salami of radius varying from 1 to $2 \mathrm{~cm}$, are reported in Figure la. It can be see that the salami size affects significantly the mass transfer, in fact, doubling the salami radius, the final value of dry basis moisture content decreases of about 0.2 . This aspect highlights that the assessment of size is an important aspect for the ripening stage.

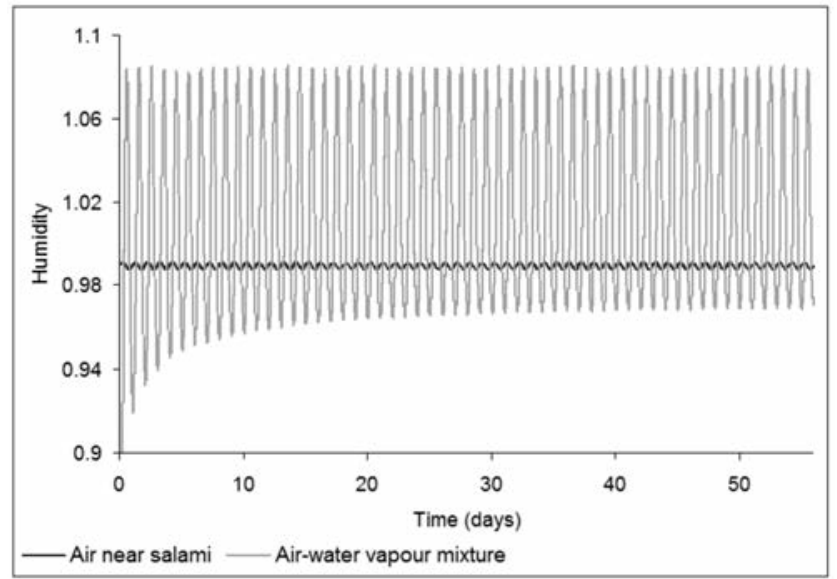

Figure 4. Trend of air humidity near to salami and of air-water vapour mixture humidity, during $\mathbf{5 6}$ days of storage.

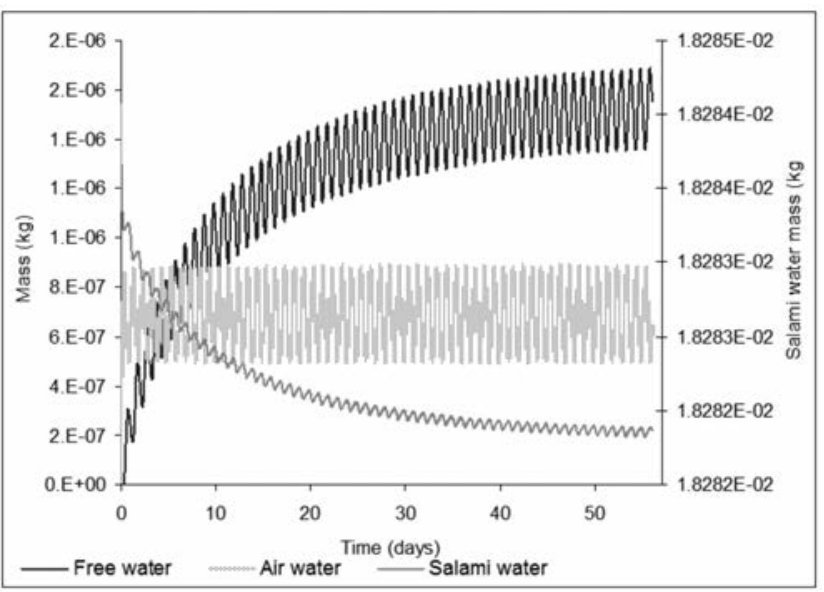

Figure 5. Mass of water free (available for evaporation and condensation), water in packaging air and in salami.

The mean moisture contents on dry basis, for a relative humidity of 65,75 and $85 \%$ are reported in Figure 1b. The humidity not affects significantly the mass transfer, in fact it is possible observe a moisture content decrease of about 0.05 , passing from a humidity of 0.65 to 0.85 $\%$. To evaluate the effect of ripening temperature on the mass transfer, the mean dry basis moisture content, determined numerically, for a ripening temperature of $15,20,25$ and $30^{\circ} \mathrm{C}$, are reported in Figure 1c. Passing from 15 to $30^{\circ} \mathrm{C}$, only a moisture content decrease of 0.05 was observed, therefore it possible to assert, also in this case, that temperature not affect significantly the mass transfer inside of salami.

Dry basis moisture content as function of ripening time and position inside of salami is reported in Figure 1d. In the salami centre $(r=0)$, moisture content is unchanged, while on the surface, is in equilibrium with the environment. A moisture content decrease along the salami radius was observed.

In figure 2 the simulated moisture concentration inside of a salami characterized by a radius of $1 \mathrm{~cm}$, during 12 days of ripening is reported. It can be seen that after 12 days of ripening, the moisture inside the salami is not uniformly placed, there is a considerable difference 
between centre (about $15000 \mathrm{~mol} \mathrm{~m}^{-3}$ ) and surface (about 45000 mol m${ }^{-3}$ ). To validate the storage model, experimental and calculated values of moisture content on dry basis determined after 56 days of storage in waterproof packaging at temperature variable from 20 to $30^{\circ} \mathrm{C} 75 \%$ of humidity, were compared.

Experimentally, a slightly lower moisture content (0.95) than the initial one (0.97) was obtained. By using the model, after 56 days of storage, the moisture content value decreases of only about 0.01 (final value of about 0.96 ). This result shows that the numerical model is able to reproduce the mass transfer, evaporation and condensation phenomena during the storage of packaged salami.

Room temperature variation produces condensation and evaporation phenomena on the salami surface causing small oscillations. In fact the water can not diffuse out of salami because the waterproof packaging makes closed the system.

Dry basis moisture content as function of storage time and position inside of salami is reported in Figure 3. It can be seen that the moisture content variation is vary small and that in the salami centre $(r=0)$, is unchanged, while on the surface $(r=1)$, evaporation and condensation phenomena causing more variation. Particularly, when temperature increases, water evaporates and moisture content decreases, while when temperature decrease, water condenses and moisture content increases.

Trend of air humidity near to salami and of air-water vapour mixture humidity, during 56 days of storage, are reported in figure 4 . Air humidity is characterized by more small variation (from 0.991 to 0.988 ), compared to air-water vapour mixture humidity (from 0.94 to 1.08 ). These trends, due to temperature oscillation, control evaporation and condensation phenomena, in fact when air-water vapour mixture humidity is greater than 1, water free condenses, on the contrary, when it is less or equal to 1 , water free evaporates.

Mass changes of liquid water (available for evaporation and condensation), in packaging air and inside of salami, during storage, are shown in figure 5 . According to figure 3 , it can be seen that salami water mass, decreases very little during the storage. This reduction causes a free water increase during about the first twenty days of storage. In fact the water moves from salami to packaging air until the air is saturated.

\section{Conclusions}

The numerical models allowed to study the mass transfer of the water inside of salami, during the ripening and storage phases, with a detail unreachable by any experimental technique.

The results of the models, in integral form, are in good agreement with those experimentally observed.

The model clarify the mass diffusion mechanism that move moisture from the inner part of salami to its surface: whatever are the environmental conditions, the moisture in the headspace reach an equilibrium with the moisture inside the meat. During the conservation the moisture concentration tends, by mass diffusion, to became uniform in space, flowing from the centre to the periphery. As the temperature decrease, the head-space air became over-saturated releasing some water. This liquid state water drops on the salami surface, significantly compromising the conservation conditions. During the conservation time, every temperature oscillation activates this water movement mechanism.

Ultimately the numerical model represents a powerful and versatile industrial instrument and being parametric, wide spanning data input regarding time, ripening and storage temperatures, size and type of sausage etc., can be tested.

\section{References}

Baldini P., Cantoni E., Colla F., Diaferia C., Gabba L., Spotti E., Marchelli R., Dossena A., Virgili E., Sforza S., Tenca P., Mangia A., Jordano R., Lopez M.C., Medina L., Coudurier S., Oddou S., Solignat G. 2000. Dry sausages ripening: influence of thermohygrometric conditions on microbiological, chemical and physico-chemical characteristics. Food Res Int, 33:161-170.

Bertolini M., Ferretti G., Grassi A., Montanari R. 2006. Seasoning process design optimization for an ascending flow ripening chamber. J. Food Eng, 77:529-538.

Campbell-Platt G., Cook P.E. 1995. Fermented meats. Glasgow: Blackie Academic and Professional.

Costa-Corredor A., Pakowski Z., Lenczewski T., Gou P. 2010. Simulation of simultaneous water and salt diffusion in dry fermented sausages by the Stefan-Maxwell equation. J. Food Eng, 97:311-318.

Floury J., Le Bail A., Pham Q.T. 2008. A three-dimensional numerical simulation of the osmotic dehydration of mango and effect of freezing on the mass transfer rates. J. Food Eng, 85:1-11.

Graiver N., Pinotti A., Califano A., Zaritzky N. 2006. Diffusion of sodium chloride in pork tissue. J. Food Eng, 77:910-918.

Grassi A., Montanari R. 2005. Simulation of the thermodynamic patterns in an ascending flow ripening chamber. J. Food Eng, 68:13-123.

Hansen C.L., van der Berg F., Ringgaard S., Stodkilde-Jorgensen H., Karlsson A.H. 2008. Diffusion of $\mathrm{NaCl}$ in meat studied by $1 \mathrm{H}$ and 23Na magnetic resonance imaging. Meat Sci, 80:851-856.

Lemus-Mondaca R.A., Zambra C.E., Vega-Gálvez A., Moraga N.0. 2013. Coupled 3D heat and mass transfer model for numerical analysis of drying process in papaya slices. J. Food Eng, 116:109-117.

Mirade P-S. 2008. Computational fluid dynamics (CFD) modelling applied to the ripening of fermented food products: Basics and advances. Trends Food Sci Tech, 19:472-481.

Mujumdar. A.S., Menon. A.S., 1995. Drying of Solids, pp. 1-46, in A.S. Mujumdar (Ed.) Handbook of Industrial Drying, 2nd Edition, Marcel Dekker, New York.

Norton T., Sun D.W. 2006. Computational fluid dynamics (CFD) e an effective and efficient design and analysis tool for the food industry: a review. Trends Food Sci Tech, 17:600-620.

Polatoğlu B., Vildan Beşe A., Kaya M. \& Aktaş N. 2011. Moisture adsorption isotherms and thermodynamics properties of sucuk (Turkish dry-fermented sausage). Food Bioprod Process, 89:449-456.

Rizzi A. 2003. Development of a numerical model for the fluid dynamic simulation of an ascending flow ripening chamber. J. Food Eng, 58:151-171.

Sabadini E., Carvalho B.C., do A. Sobral P.J., Hubinger M.D. 1998. Mass transfer and diffusion coefficient determination in the wet and dry salting of meat. Drying Tech, 16:2095-2115.

Sakin M., Kaymak-Ertekin F., Ilicali C. 2007. Simultaneous heat and mass transfer simulation applied to convective oven cup cake baking. J. Food Eng, 83:463-474.

Scott G., Richardson P. 1997. The application of computational fluid dynamics in the food industry. Trends Food Sci Tech, 8:119-124.

Smale N. J., Moureh J., Cortella G. 2006. A review of numerical models of airflow in refrigerated food applications. Int J. Refr, 29:911-930.

Toldrá F. 2006. Meat fermentation In Y. H. Hui, E. Castell-Perez, L. M. Cunha, I. Guerrero-Lagarreta, H. H. Liang, Y. M. Lo, D. L. Marshall, W. K. Nip, F. Shahidi, F. Sherkat, R. J. Winger, \& K. L. Yam (Eds.), Handbook of food science, technology and engineering, Florida, USA: CRC Press.

Toldrá F., Nip W. K., Hui Y. H. 2007. Dry-fermented sausages: An overview. In F. Toldrá (Ed.), Handbook of fermented meat and poultry. Iowa, USA: Blackwell Publishing. 
Unal B.S., Erdog du F., Ekiz H.I., Ozdemir Y. 2004. Experimental theory, fundamentals and mathematical evaluation of phosphate diffusion in meats. J. Food Eng, 65:263-272.

Verboven P., Flick D., Nicolaı B.M. Alvarez G. 2006. Modelling transport phenomena in refrigerated food bulks, packages and stacks: basics and advances Int J. Refr, 29:985-997.

Wang L., Sun D.W. 2003. Recent developments in numerical modelling of heating and cooling processes in the food industry e a review. Trends Food Sci Tech,14:408-423.

Xia B., Sun D.W. 2002. Applications of computational fluid dynamics
(CFD) in the food industry: a review. Comput Electron Agric, 34:524.

Zanardi E., Ghidini S., Conter M., Ianieri A. 2010. Mineral composition of Italian salami and effect of $\mathrm{NaCl}$ partial replacement on compositional, physico-chemical and sensory parameters. Meat Sci, $86: 742-747$.

Zeuthen P. 1995. Historical aspects of meat fermentations. In G. Campbell-Platt, \& P. E. Cook (Eds.), Fermented meats. Glasgow, UK: Blackie Academic \& Professional. 